\title{
EVALUATION OF BREAST MASSES USING MAMMOGRAPHY, SONOGRAPHY AND ITS CORRELATION
}

\author{
Ramesh Parate1, Vipin Kasat ${ }^{2}$, Rahul Solanke 3 \\ ${ }^{1}$ Associate Professor, Department of Radiodiagnosis, Government Medical College, Nagpur, Maharashtra, India. \\ 2Junior Resident, Department of Radiodiagnosis, Government Medical College, Nagpur, Maharashtra, India. \\ 3Junior Resident, Department of Radiodiagnosis, Government Medical College, Nagpur, Maharashtra, India.

\section{ABSTRACT}

\section{BACKGROUND}

Breast diseases are common in females. In developing countries like India, females are unaware of breast pathologies and are hesitant to reveal, hence they are detected usually in advanced stages. Breast cancer is the most common cause of cancer deaths in women and overall fifth common cause of cancer deaths in the world.

Aims and Objectives: To study the specificity of mammography and ultrasonography separately and in combination for detection of breast masses (Ultrasonography-Mammography Correlation); To study the investigations to evaluate various breast masses; To describe suitable indications, advantages and limitations of each technique compared with other available modalities; To study the mimics of breast masses; To have histopathology follow-up and retrospective evaluation with imaging findings to improve diagnostic skills in series of 88 patients complaining of breast mass diagnosed radiologically.

\section{MATERIALS AND METHODS}

The study was a descriptive study, carried out in the Department of Radiodiagnosis, for a period of 1-year extending from October 2016 to October 2017 in female patients complaining of breast mass. A well-informed written consent was obtained from them. Histopathology follow-up was obtained from either biopsy or post-operative tissue.

\section{RESULTS}

Ultrasonography and mammography was done in most of the cases. They were sufficient to diagnose the lesion in most of the cases, especially in benign breast masses. Total 88 patients complaining of breast mass in one or both breasts were examined and evaluated with USG and mammography. The lesions were confirmed on histopathology (FNAC/biopsy). Out of 9 diagnosed malignancies, 1 lesion was missed on mammography and 1 lesion was missed on ultrasonography. One of them was missed on both. For malignancies, specificity of mammography is $93.3 \%$ and that of ultrasonography is $86.67 \%$. Combining both the modalities, specificity is near 97\%. Out of total 60 abnormal breasts, 6 were missed on USG and 10 were missed on mammography. Combining both the modalities only 2 lesions were missed and were diagnosed on histopathology alone.

\section{CONCLUSION}

Our study confirms the higher combined sensitivity rate for ultrasonography and mammography for detection of breast masses including malignancies. USG is useful in cystic lesions, ectasias, infections, pregnancy-lactation and dense breast evaluation and for image guidance, whereas mammography is useful in detecting microcalcifications, spiculated masses for early detection of malignancies and for stereotactic biopsies. To suggest single modality, ultrasonography is better in younger population and BIRAD 1, 2 and 3 lesions. Whereas, mammography is better in older population and BIRAD 4 and 5 lesions. However, sonomammographic correlation is best in both.

\section{KEY WORDS}

Breast Lump.

HOW TO CITE THIS ARTICLE: Parate R, Kasat V, Solanke R. Evaluation of breast masses using mammography, sonography and its correlation. J. Evolution Med. Dent. Sci. 2018;7(23):2823-2828, DOI: 10.14260/jemds/2018/637

\section{BACKGROUND}

Breast diseases are common in females. In developing countries like India, females are unaware of breast pathologies and are hesitant to reveal, hence they are detected usually in advanced stages. Various benign breast lesions like fibroadenomas, simple cyst, breast abscess, galactocele, duct ectasia, enlarged lymph nodes and different malignancies are common pathologies of female breast.

'Financial or Other Competing Interest': None.

Submission 13-02-2018, Peer Review 20-05-2018,

Acceptance 28-05-2018, Published 04-06-2018.

Corresponding Author:

Dr. Vipin Kasat,

Department of Radiodiagosis,

Government Medical College,

Hanuman Nagar, Nagpur-440009,

Maharashtra, India.

E-mail: drvskasat@gmail.com

DOI: $10.14260 /$ jemds $/ 2018 / 637$
Breast cancer is the most common cause of cancer deaths in women and overall fifth common cause of cancer deaths in the world.[1]

Delay in the detection causes malignancy to progress in advanced stage. Usually, it comprises of inoperable masses, metastasis (Bone, Brain, Lung) and eventually leads to mortality. Albert Solomon (1913) for the first time after the invention of $\mathrm{x}$-rays studied, the breast under $\mathrm{x}$-rays and suggested that $\mathrm{x}$-rays can be used for diagnostic purpose for breast pathologies.[2] Mammography was used primarily for early detection of malignancies in their curable stages, to decrease the malignancy related mortality. It is a screening tool which is easily available, cheap and fairly accurate with minimal radiation to detect microcalcifications, speculated masses and small lymph nodes seen in malignancies.[3] Incidence of breast cancer can be reduced by $30 \%$ by the routine mammographic screening of healthy women. ${ }^{[4,5]}$ In the history of USG in 1951 Wild and Reid[6] first developed 
equipment specially designed for breast scanning. Once limited for differentiating between solid and cystic lesions, breast ultrasound now proposes an attempt to characterise the breast nodules and to differentiate them as benign and malignant.[7] Breast ultrasound has evolved as an indispensable problem solving tool in patients with dense breasts, post-radiation breasts, and women less than 35 years of age, pregnant and lactating patients.[8] In our study, an attempt was made to evaluate various breast masses using USG and mammography separately and in combination to describe suitable indications, advantages and limitations of each technique compared with other available modalities and to differentiate the benign breast lesions from the malignant ones.

\section{MATERIALS AND METHODS}

The study was a descriptive study carried out in the Department of Radiodiagnosis for a period of 1 year extending from October 2016 to October 2017 in patients complaining of breast masses. Well informed written consent was obtained from them. Histopathology follow-up was obtained from either biopsy or post-operative tissue.

\section{Study Design}

Descriptive study.

\section{Inclusion Criteria}

1. All patients with clinically palpable breast masses. USG proven solid breast masses or complex cystic lesions.

2. No obvious breast mass on palpation, but prominent axillary nodes.

3. Females with clinical signs of redness over the breast area, nipple retraction, dryness and altered shape.

4. $\mathrm{K} / \mathrm{C} / \mathrm{O}$ carcinoma breast with mastectomy done on one side.

5. Family history of breast mass in first-degree relative.

\section{Exclusion Criteria}

1. Very large and very tender breast.

2. Very apprehensive patient.

Every patient who is complaining of lump/ pain in breast were taken. The sample size was taken for convenience. The study was descriptive study carried out in the Department of Radiodiagnosis for a period of 1-year extending from October 2016 to October 2017 in female patients complaining of breast mass. A well-informed written consent was obtained from them. Histopathology follow-up was obtained from either biopsy or post-operative tissue.

\section{USG Machine}

Philips HD 11 XE, GE SQ8, Philips IU USG of the breasts and axillary region was done in supine position in presence of female attendant.

\section{Mammography Machine}

Allengers machine with Agfa special mammography cassettes. Craniocaudal and Mediolateral Oblique views are taken in the presence of female attendant.

\section{Ultrasonography[9,10,11]}

\section{Advantages}

a) Better in detection of cystic lesions and its contents. b) Better in infective pathologies and tender pathologies.

c) Dense breasts are better evaluated.

d) No radiation exposure, so better in lactation and pregnancy.

e) Vascularity can be commented.

f) It is real time and whole breast region can be evaluated even in large breasts.

g) Flat bony lesions and mimics of breast masses can be evaluated better.

\section{Limitations}

a) Microcalcifications can be missed.

b) Fat and air can obscure lesion.

c) Relatively well-defined lesions can be labelled as benign.

d) Sensitivity depends on operator.

e) Isoechoic and multicentric lesions can be missed.

\section{Mammography[9,10,12]}

Advantages

a) Better in detection of microcalcifications.

b) Better in detection of spiculated masses.

c) Multiple lesions with spacial relation to each other can be better made out.

d) Stereotactic biopsy can be done.

\section{Limitations}

[a] Solid and cystic lesions, not better differentiated.

[b] Not done in pregnancy and lactation.

[c] Not done in very painful or tender breasts.

[d] Sensitivity declines in dense breasts or breasts infections.

[e] Not done on flat masses and mimics of breast masses.

[f] Very large breasts could not be evaluated adequately

[g] Complete visualisation of breast is not possible in single view.

\section{Confirmation}

[1] FNAC/Biopsy in doubtful cases, post-operative follow-up in operative cases.

[2] In cases of simple cysts and galactocele, no histopathology confirmation was done. Aspiration of cyst was done to confirm.

[3] No histopathology done in cases of normal ultrasound findings and normal mammography in patients complaining of apparent mass felt on clinical examination. Such patients refused to give consent for invasive histopathology study after normal reports and they were labelled as normal. Hence, sensitivity and positive predictive value could not be obtained. The values of specificity, negative predictive value, accuracy for ultrasound and mammography in overall breast masses (also separately in malignant lesions) were obtained when used separately and in combination.

\section{Fibroadenomas}

Clinically, patients present with the history of freely movable lump in one or both breasts since few months to years, usually painless.[13] Nearly, one-third of them (8 patients) had previous history of similar mass being operated in one or both breasts. Out of total 21 patients of fibroadenomas, most of them were younger (Figure 1). On mammography, fibroadenoma shows well-marginated soft tissue density, radio-opacity with or without typical benign type of 
circumferential and concentric calcifications (Popcorn calcification).[14,15] Many of the fibroadenoma do not show calcification. On ultrasonography, well-defined round-to-oval lesion with homogeneous echotexture and width greater than depth. Out of total 21 fibroadenomas, 1 was missed on ultrasound and 5 were missed on mammography, but combining both no fibroadenoma was missed.

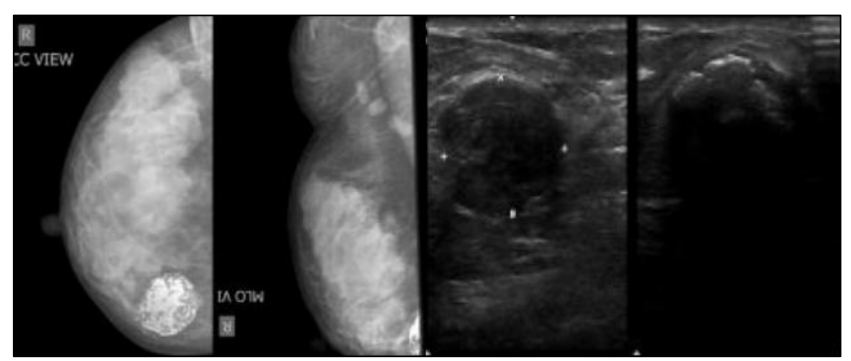

Figure 1. A Case of Right-Sided Fibroadenoma showing a 35 years old Female with Complaints of Lump on Right Breast since 3 Months

\section{Malignancies}

Malignant masses present clinically with lump in the breast, retracted nipple, pain and bloody discharge and ulceration over the skin. Malignant lesions on mammography reveal irregular mass, spiculated or lobulated margins, focal asymmetry, lesion appears taller than wider, retracted nipple, calcification may be linear, branching, granular, clustered with surrounding architectural distortion.[16,17]

Out of 9 diagnosed malignancies, one was missed on mammography, therefore specificity of mammography is 93.3\%. One lesion was missed on USG, therefore specificity of ultrasonography is $93.3 \%$. Combining both the modalities, specificity is near $100 \%$.

Chances of malignancies were higher in patients complaining of breast mass in elderly patients than younger patients.

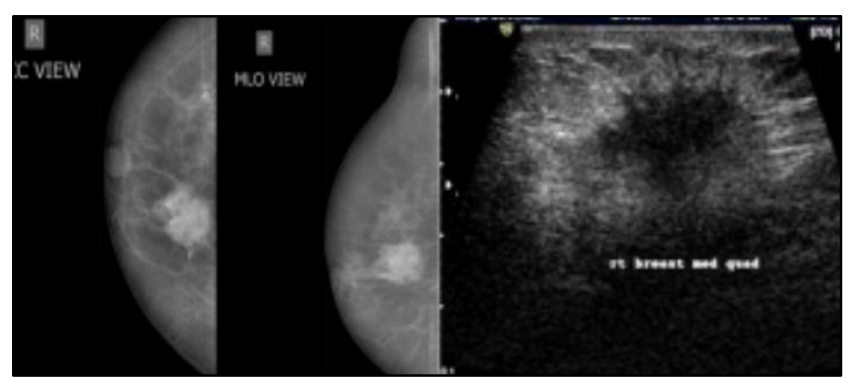

Figure 2. A Case of Ductal Malignancy. Microcalcifications involving Superolateral Quadrant in a 55 years old Female with Lump on Right Breast since 6 Months



Figure 3. A Case of Ductal Malignancy in a 40 years old Female with Complaints of Gradually Increasing Lump on the Right Breast since 6 Months. Mammography reveals Focal Asymmetry with surrounding Architectural Distortion involving Superolateral Quadrant of Right Breast

\begin{tabular}{|c|c|c|c|}
\hline $\begin{array}{c}\text { Total } \\
\text { Number of } \\
\text { Malig- } \\
\text { nancies }\end{array}$ & $\begin{array}{c}\text { Detected } \\
\text { only by } \\
\text { Mammo- } \\
\text { graphy }\end{array}$ & $\begin{array}{c}\text { Detected } \\
\text { only by } \\
\text { Ultrasono- } \\
\text { graphy }\end{array}$ & $\begin{array}{c}\text { Detected by } \\
\text { Mammography + } \\
\text { Ultrasonography }\end{array}$ \\
\hline 9 & 8 & 8 & 9 \\
\hline
\end{tabular}

\begin{tabular}{|c|c|c|c|}
\hline & USG & Mammography & Total \\
\hline Fibroadenoma & 20 & 16 & 21 \\
\hline Malignancy & 8 & 8 & 9 \\
\hline
\end{tabular}

\section{Cystic Lesions}

Cystic lesions present clinically with lump in the breast. On mammography cystic lesions appear as well-defined soft tissue density lesions and could not be differentiated from solid masses like fibroadenoma.[18,19] On ultrasonography, cystic lesions can be easily diagnosed. For cystic lesions like simple cysts, multiple cysts in perimenopausal fibrocystic changes, galactocele and in duct ectasia ultrasonography is far better than mammography, showing all the patients with duct ectasia were above 40 years had complaints of turbid discharge from the nipple. Mammograms in most of the duct ectasia patients were labelled as normal with mixed parenchymal pattern (P1/ACR 2 pattern), except in one patient in fatty breast was given. Ultrasonography proved to be problem solving in all the cases of duct ectasia. [20,21]

Out of total 15 perimenopausal fibrocystic changes, 11 patients were correctly diagnosed on mammography (specificity 73.3\%), but all the lesions could be correctly picked up on ultrasonography (Specificity 100\%) in appropriate clinical setting. Simple cysts on ultrasound were aspirated and were not subjected to biopsy, only one of them needed total of three aspirations. [22] 


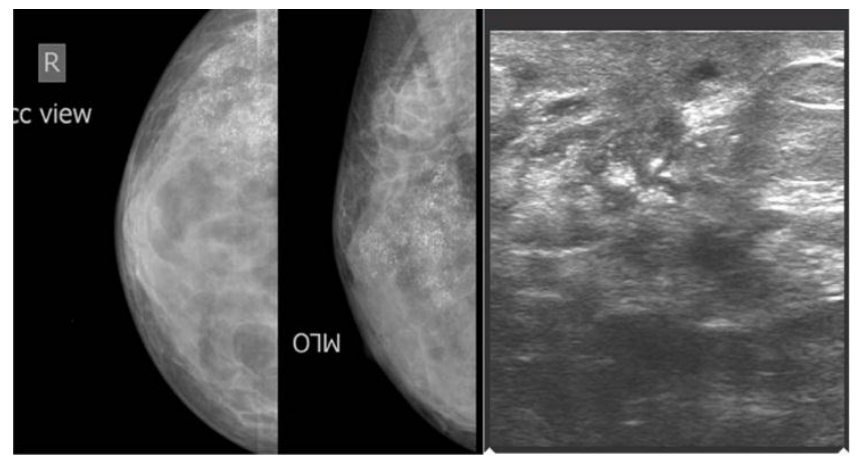

Figure 4. A Case of Ductal Malignancy. Microcalcifications involving Superolateral Quadrant in a 65 years old Female with Lump on Right Breast since 1 Year

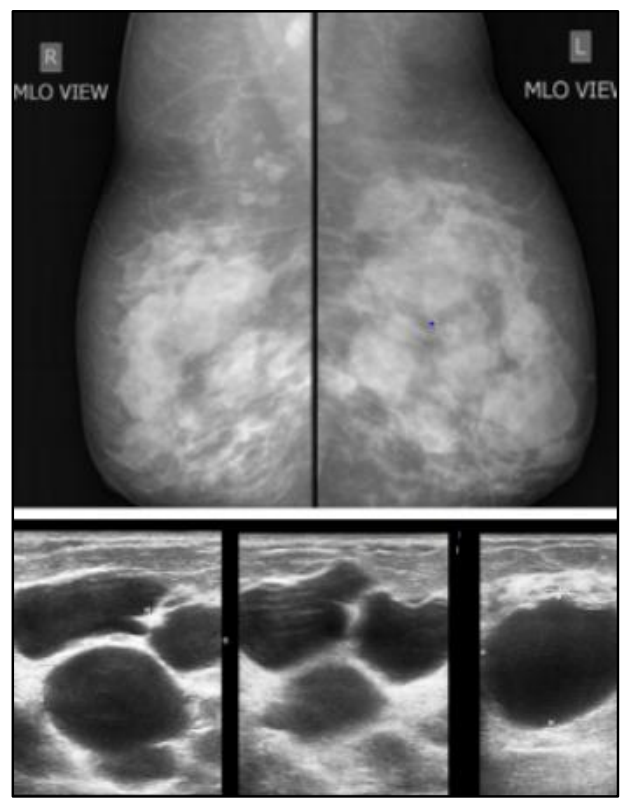

Figure 5. A Case of Bilateral Cystic changes in a 40 years old female with Complaints of Lump on both Breasts since 4 Months. Mammography (a) reveals Bilateral Multiple Soft Tissue Density Lesions without obvious Architectural Distortion. Sonography (b) revealed Multiple Cystic Lesions.

\section{Mimics of Other Lesions}

Which are extra breast in origin, present as swelling or mass in the breast. Our study includes 4 such cases involving pectoralis major muscle, haemangioma, chondrosarcoma of the rib, breast hydatid and malignant pleural mesothelioma. $[23,24,25]$ Most of these masses were hard, tense or flat, hence mammography could only be done on soft mass like pectoralis major muscle. Haemangioma,[26,27] in most of these cases cross-sectional imaging was necessary to know the extent of the lesion, adjacent bone and pleura involvement, vascularity and ultimately operability of the lesion. Post-operative histopathology was done in haemangioma and breast hydatid, whereas biopsy was done for confirmed diagnosis in chondrosarcoma and malignant pleural mesothelioma.

\section{Follow-Up}

In breast malignancies, modified radical mastectomy with MRI is important in relatively difficult cases to differentiate between malignant and benign lesions, degree of invasion into the surrounding soft tissue and perfusion pattern and hence is more reliable. To determine multifocality, to differentiate scar tissue and recurrent cancer, to evaluate breast implants. It is costly and unaffordable in many patients. CT scan is important in bony lesions to determine bony destruction and intra-thoracic extension and in patients who cannot afford costly investigations like MRI.

\section{Statistical Analysis}

All data was collected and verified. Collected data was subjected to SPSS (version 20) for analysis. Data was expressed as frequencies for all the parameters. Chi-square test was performed to visualise the difference. P-value 0.05 was considered significant.

\section{RESULTS}

In this study, total 88 patients (Table 1) were complaining of breast mass in one or both breasts were examined clinically and evaluated with USG and mammography. The lesions were confirmed on histopathology (biopsy/ tissue from postoperative specimens/ aspiration) as per individual case. 28 out of total 88 patients were labelled normal and they were not followed up. Total 60 patients were abnormal and categorised according to the pathology (Table 2).

\begin{tabular}{|c|c|}
\hline $\begin{array}{c}\text { Number of Patients in } \\
\text { Specific Age Group }\end{array}$ & $\begin{array}{c}\text { Age Group Number of } \\
\text { Patients }\end{array}$ \\
\hline $20-25$ & 0 \\
\hline $26-30$ & 3 \\
\hline $31-35$ & 5 \\
\hline $36-40$ & 15 \\
\hline $41-45$ & 25 \\
\hline $46-50$ & 15 \\
\hline $51-55$ & 10 \\
\hline $55-60$ & 10 \\
\hline 60 and Above Table 1 \\
\hline \multicolumn{2}{|c}{} \\
\hline \multicolumn{2}{|c}{} \\
\hline
\end{tabular}

\begin{tabular}{|c|c|}
\hline BIRADS 0 & 28 \\
\hline BIRADS 1 & 3 \\
\hline BIRADS 2 & 41 \\
\hline BIRADS 3 & 7 \\
\hline BIRADS 4 & 3 \\
\hline BIRADS 5 & 2 \\
\hline BIRADS 6 & 4 \\
\hline Table 2. Number of various Pathologies in Breast \\
according to BIRADS Classification
\end{tabular}

\begin{tabular}{|c|c|c|}
\hline $\begin{array}{c}\text { Diagnostic } \\
\text { Potential of } \\
\text { Mammography }\end{array}$ & $\begin{array}{c}\text { Diagnostic } \\
\text { Potential of USG }\end{array}$ & $\begin{array}{c}\text { Diagnostic } \\
\text { Potential of } \\
\text { Mammography + } \\
\text { USG }\end{array}$ \\
\hline Specificity-78.6\%. & Specificity-86.9\% & Specificity-97.6\%. \\
\hline
\end{tabular}

\section{DISCUSSION}

Breast masses are common in female and amongst all the breast masses, malignant masses are the most feared. Breast cancer is the commonest cause of cancer mortality in females, whereas breast cancer in men accounts for only $0.7 \%$ of all the breast masses.

Patients with palpable breast lesion commonly present for radiology evaluation. Various imaging techniques like mammography, ultrasonography, MRI, scintimammography 
and PET are now available. Mammography is the primary method of detection and diagnosis of breast disease with sensitivity of $85 \%$ - 95\%. The specific mammographic features of the breast mass help in diagnosis. Benign lesions show round-to-oval shape, well-defined margins, few lobulations, low soft tissue density and fat containing lesions. Malignant lesions are high soft tissue density, irregular margins, multiple lobulations and spiculations with or without microcalcifications.

Mammography in breast mass can be used to look for microcalcifications and architectural distortion, speculated margins and hence to determine the potential malignant nature of the lesion and also to screen for occult disease in the surrounding tissue. Mammography proved to be an effective diagnostic tool for defining the benign and malignant characteristics of palpable breast mass. Mammography is nearly $87 \%$ accurate in detecting cancer. Its specificity is $88 \%$ and its positive predictive value may be as high as $22 \%$. But the false negative findings on mammography on evaluation of palpable breast mass is high, estimated between $4 \%$ and $12 \%$. Hence, many of the times, other modalities are needed to compliment the primary diagnosis given on mammography. Ultrasonography is the perfect adjunct to the mammography, since both the modalities are easily available, relatively cheaper and can take relatively less time. Initially, Ultrasonography was only used to differentiate solid from cystic masses. Ultrasonography effectively differentiates solid lesion from cystic which account for nearly $25 \%$ breast lesions, now it can be used to evaluate breasts usually below 35 years of age. In the breasts where solid lesions and cysts are obscured by mammography due to dense fibroglandular tissue, ultrasonography help in diagnosis and to decrease the number of surgical biopsies. It is necessary to evaluate the complex cysts or cysts which need repeated aspiration since they can harbour malignancy. Ultrasonography can be used to differentiate benign from malignant lesions with negative predictive value of $99.5 \%$, specificity of $67.8 \%$ and overall accuracy of $72.9 \%$ (Stavros et al). The specific sonographic features determining the benign nature of the lesion include intense hyperechogenicity, ellipsoid shape, gentle lobulations, thin echogenic pseudocapsule and less than four gentle lobulations. Malignant nature of the lesion is given by spiculations, angular margins, shadowing, microlobulations and microcalcifications.

Though a definitive diagnosis is possible with noninvasive imaging procedures, for most lesions histopathology or cytology (biopsy/ FNAC) are proven tools and essential for obtaining confirmed diagnosis. It is important to be aware about the other extra breast lesions which can be present with palpable breast masses, chest wall lesions, muscular and pleural lesions, bony masses and hydatid disease can be present clinically with breast swelling. An appropriate crosssectional imaging can help. Finally, though mammography and ultrasonography have their own advantages and limitations, no single investigation is $100 \%$ accurate but combination of mammography and ultrasonography can yield near $100 \%$ results.

\section{CONCLUSION}

Our study confirms the higher combined specificity for ultrasonography and mammography for detection of breast masses including malignancies. USG is better in cystic lesion, ectasia, infection and inflammatory conditions, pregnancylactation, dense breast evaluation and real time image guidance; whereas mammography is better in detecting microcalcifications, spiculated masses for early detection of occult malignancies and for stereotactic biopsies. Ultrasonography and mammography cannot replace each other, but to suggest single modality ultrasonography is better in younger population and BIRAD 1, 2 and 3 lesions. Whereas, mammography is better in older population and BIRAD 4 and 5 lesions. However, sonomammographic correlation is best in both.

Extra breast lesions can mimic breast mass. Its awareness and careful cross-sectional imaging can be problem solving. Mammography does not help much in these cases.

\section{REFERENCES}

[1] World Health Organization (2006), Cancer. Fact Sheet (No. 297), Geneva. http://www.who.int/mediacentre/factsheets/fs297/e $\mathrm{n} /$ print.html

[2] Gold RH. The evolution of mammography. Radiologic Clinics of North America 1992;30(1):1-19.

[3] Khatun H, Tareak-Al-Nasir, Enam S, et al. Correlation of fine needle aspiration cytology and its histopathology in diagnosis of breast lumps. Bangladesh Medical Research Council Bulletin 2002;28(2):77-81.

[4] Morris KT, Vetto JT, Petty JK, et al. A new score for the evaluation of palpable breast masses in women under age 40. American Journal of Surgery 2002;184(4):3467.

[5] Berg WA, Gutierrez L, NessAiver MS, et al. Diagnostic accuracy of mammography, clinical examination, US and MR imaging in preoperative assessment of breast cancer. Radiology 2004;233(3):830-49.

[6] Wild JJ, Reid JM. Further pilot echographic studies on the histologic structure of tumors of the living intact human breast. American Journal of Pathology 1952;28(5):839-61.

[7] Clarke D, Sudhakaran N, Gateley CA. Replace fine needle aspiration cytology with automated core biopsy in the triple assessment of breast cancer. Annals of The Royal College of Surgeons of England 2001;83(2):110-2.

[8] Schoonjans JM, Brem RF. Fourteen-Gauge ultrasonographically guided large-core needle biopsy of breast masses. Journal of Ultrasound Med 2001;20(9):967-72.

[9] Giordano SH. A review of the diagnosis and management of male breast cancer. Oncologist 2005;10(7):471-9.

[10] Bruening W, Uhl S, Fontanarosa J, et al. Noninvasive diagnostic tests for breast abnormalities: update of a 2006 review. Agency for Healthcare Research and Quality (US) 2012. www.effectivehealthcare.ahrq.gov/reports/final.cfm

[11] Prasad SN, Houserkova D. A comparison of mammography and ultrasonography in the evaluation of breast masses. Biomedical Papers of the Medical Faculty of The University Palacky, Olomouc, Czech Republic 2007;151(2):315-22. 
[12] Taori K, Dhakate S, Rathod J, et al. Evaluation of breast masses using mammography and sonography as first line investigations. Open Journal of Medical Imaging 2013;3:40-9.

[13] Lee HC, Ooi PJ, Poh WT, et al. Impact of inadequate fine-needle aspiration cytology on outcome of patients with palpable breast lesions. Aust and New Zealand Journal Surg 2000;70(9):656-9.

[14] Chakraborti KL, Bahl P, Sahoo M, et al. Magentic resonance imases: comparison with mammography. Indian Journal of Radiology and Imaging 2005;15(3):381-7.

[15] Evans WP. Breast masses. Appropriate evaluation. RCNA 1995;33(6):1085-108.

[16] Kerlikowske K, Smith-Bindman R, Ljung BM, et al. Evaluation of abnormal mammography results and palpable breast abnormalities. Annals of Internal Medicine 2003;139(4):274-84.

[17] Kumle M, Weiderpass E, Braaten T, et al. Use of oral contraceptives and breast cancer risk: the NorwegianSwedish Women's Lifestyle and Health Cohort Study. Cancer Epidemiol Biomarkers \& Prevention 2002;11(11):1375-81.

[18] Shetty MK, Shah YP, Sharman RS, et al. Prospective evaluation of the value of combined mammographic and sonographic assessment in patients with palpable abnormalities of the breast. Journal of Ultrasound in Medicine 2003;22(3):263-8.

[19] Gurung G, Ghimire RK, Lohani B. Mammographic evaluation of palpable breast masses with pathological correlation: a tertiary care centre study in Nepal. Journal of Institute of Medicine 2010;32:21-5.
[20] Moss HA, Britton PD, Flower CD, et al. How reliable is modern breast imaging in differentiating benign from malignant breast lesions in the symptomatic population? Clinical Radiology 1999;54(10):676-82.

[21] Kolb TM, Lichy J, Newhouse JH. Comparison of the performance of screening mammography, physical examination and breast US and evaluation of factors that influence them: an analysis of 27,825 patient evaluations. Radiology 2002;225(1):165-75.

[22] Barlow WE, Lehman CD, Zheng Y, et al. Performance of diagnostic mammography for women with signs or symptoms of breast cancer. Journal of the National Cancer Institute 2002;94(15):1151-9.

[23] Dennis MA, Parker SH, Klaus AJ, et al. Breast biopsy avoidance: the value of normal mammograms and normal sonograms in the setting of a palpable lump. Radiology 2001;219(1):186-91.

[24] Weinstein SP, Conant EF, Orel SG, et al. Retrospective review of palpable breast lesions after negative mammography and ultrasonography. J of Women's Imaging 2000;2:15-8.

[25] Stavros AT, Thickman D, Rapp CL, et al. Solid breast nodules: use of sonography to distinguish between benign and malignant lesions. Radiology 1995;196(1):123-134.

[26] Ueno E, Tohno E, Itoh K. Classification and diagnostic criteria in breast echography. Journal of Medical Ultrasonics 1986;13(1):19-31.

[27] Hindle WH, Payne PA, Pan EY. The use of fine-needle aspiration in the evaluation of persistent palpable dominant breast masses. American Journal of Obstetrics \& Gynecology 1993;168(6 Pt 1):1814-9. 